\title{
Estrutura da vegetação e comportamento ingestivo de novilhos em pastagem natural do Rio Grande do Sul
}

\author{
Juliana Muliterno Thurow ${ }^{1}$, Carlos Nabinger ${ }^{2}$, Zélia Maria de Souza Castilhos ${ }^{3}$, Paulo César \\ de Faccio Carvalho², Coralia Maria Oliveira Medeiros ${ }^{3}$, Mirela Dias Machado ${ }^{4}$ \\ ${ }^{1}$ Programa de Pós-Graduação em Zootecnia/UFRGS, Depto. de Plantas Forrageiras e Agrometeorologia, Cx. Postal 776, CEP: 91501-970, \\ Porto Alegre, RS. \\ 2 Departamento de Plantas Forrageiras e Agrometeorologia da UFRGS. \\ 3 Fepagro. \\ ${ }^{4}$ Estagiária da Fepagro.
}

RESUMO - O experimento foi realizado em uma pastagem natural com o objetivo de avaliar a influência do nível de oferta de forragem sobre a estrutura do pasto e o comportamento ingestivo de bovinos. Foi usado delineamento de blocos completamente casualizados, com quatro níveis de ofertas diárias de forragem (4, 8, 12 e $16 \mathrm{~kg}$ de MSFV/100 kg de PV) e duas repetições, utilizando-se o método de pastejo contínuo, com taxa de lotação variável. O aumento da oferta de forragem melhorou a participação do estrato superior na forragem disponível e determinou maior altura do estrato inferior. O aumento na altura do estrato inferior ocasionou redução no tempo de pastejo e maior tempo de ruminação no outono, no inverno e na primavera, o que indica melhoria no ambiente pastoril. No entanto, neste tipo de vegetação, o aumento da altura do estrato inferior em maior oferta de forragem não foi suficiente para que a altura atingisse os níveis preconizados para potencializar a ingestão diária de forragem. O aumento da oferta de forragem e da altura do estrato inferior determina resposta linear decrescente do tempo de pastejo, caracterizando ambiente alimentar com maior número de refeições em menor tempo.

Palavras-chave: número de refeições, oferta de forragem, pastagem natural, tempo de pastejo, tempo de ruminação

\section{Vegetation structure and ingestive behavior of steers in natural pasture in the state of Rio Grande do Sul}

\begin{abstract}
The experiment was performed in a natural pasture to evaluate the effect of the forage offer level on the pasture structure and ingestive behavior of steers. A completely randomized block design with four daily green forage offer levels (4, 812 and $16 \mathrm{~kg}$ GFDM/100 $\mathrm{kg} \mathrm{LW})$ and two replicates was used. The continuous grazing method with variable stocking rate was used. The increasing forage offer enhanced the higher strata frequency and determined higher inferior strata height. The increasing inferior stratum height decreased the grazing time and increased the ruminating time in the autumn, winter and spring, indicating improvements in the grazing environment. However, in this type of vegetation, the increase in height with increasing forage offer was not adequate to elevate the inferior strata height to the desirable levels so that the daily forage intake could be optimized. Increasing forage offer and inferior strata height indicate decreasing linear response of the grazing time and allow a feeding system with shorter time and higher number of meals.
\end{abstract}

Key Words: forage offer, grazing time, natural pasture, number of meals, rumination time

\section{Introdução}

A produção de carne bovina no Rio Grande do Sul ocorre predominantemente em pastagens naturais do bioma pampa, um ambiente alimentar extremamente heterogêneo, formado por uma vegetação de elevada diversidade florística, funcional e estrutural, onde a pressão de pastejo é determinante dessa complexidade.
Carvalho et al. (2001) destacam que a oferta de forragem afeta o desempenho animal, pois está associada à possibilidade de seleção da dieta, tanto em espécies pastejadas como da porção da planta consumida. Segundo esses autores, e particularmente em ambientes heterogêneos, o pastejo seletivo propicia que os animais consumam dieta com qualidade superior à média disponível. Neste sentido, o animal em pastejo se beneficia, ao mesmo tempo em que 
promove a heterogeneidade do ambiente pastoril, chegando a criar mosaicos de estruturas com plantas altas e baixas, dependendo da pressão de pastejo empregada (Carvalho et al., 2007).

No intuito de compreender as complexas relações entre o animal e a vegetação, o estudo do comportamento ingestivo tem sido um recurso para entender e explicar o desempenho animal, pois seus componentes são bem relacionados ao consumo de forragem (Galli et al., 1996).

Mudanças nos parâmetros do comportamento ingestivo podem permitir aos animais colher uma dieta de qualidade superior à média no ambiente. Assim, pode-se modificar seus padrões de deslocamento, preferência e ingestão em resposta a variações em espécie vegetal, estrutura das plantas, composição nutricional e disponibilidade de forragem (Palhano et al., 2006). As decisões de pastejo ocorrem por escalas espaciais e temporais sob influência de fatores bióticos e abióticos (Hodgson, 1982; Carvalho et al., 1999), pois quanto maior a heterogeneidade da pastagem maior o grau de complexidade dessas decisões (Palhano et al., 2002). Simultaneamente, o herbívoro afeta continuamente o sistema pastoril por meio do seu comportamento ingestivo, que pode alterar o fluxo de energia do ecossistema pastoril por remover superfícies de captação e promover respostas adaptativas na estrutura do dossel por meio de alterações na composição botânica e alterações arquiteturais dos indivíduos (Nabinger, 1997).

Neste contexto, o conhecimento da interface plantaanimal permite construir ambientes pastoris adequados, via manipulação da oferta de forragem, que não dificultem a ingestão de forragem. Dessa forma, objetivou-se com este trabalho verificar como a estrutura da pastagem natural, alterada por diferentes níveis de oferta de forragem, afeta as variáveis comportamentais relacionadas ao consumo animal.

\section{Material e Métodos}

Este experimento foi conduzido em pastagem natural da região da Campanha, no Rio Grande do Sul, em área pertencente à Unidade Fepagro Campanha (Fundação Estadual de Pesquisa Agropecuária), situada em Hulha Negra (31 $\left.23^{\prime} 6,1^{\prime \prime S} ; 53^{\circ} 55^{\prime} 45^{\prime \prime} \mathrm{W}\right)$. A partir de dezembro de 2003, foram impostos os níveis de oferta diária de forragem de 4, 8, 12 e $16 \mathrm{~kg}$ de matéria seca de forragem verde (MSFV)/100 kg de peso vivo, distribuídos em oito unidades experimentais (piquetes), com áreas variáveis, entre 5 e 12 ha, totalizando 70 ha. O delineamento experimental foi o de blocos completamente casualizados com medidas repetidas no tempo, quatro ofertas de forragem e duas repetições de área, de modo que o relevo e o histórico da área foram os fatores de bloqueamento.

O período experimental foi de janeiro a dezembro de 2006. No final do mês de fevereiro de 2006, efetuou-se uma roçada deixando resíduo de $20 \mathrm{~cm}$ de altura em todos os piquetes, com o intuito de controlar a vegetação do estrato superior, principalmente a dominância de chirca (Eupatorium buniifolium Hook et Arn) e da macega-estaladeira (Saccharum trinii (Hack.) Renv.).

Os animais utilizados foram novilhos de sobreano Braford com grau de sangue indefinido e peso médio inicial de $250,9+3,9 \mathrm{~kg}$, determinado em dezembro de 2005. O método de pastejo foi o de lotação contínua com taxa de lotação variável (Mott \& Lucas, 1952). A cada 28 dias, os animais eram pesados, após jejum prévio de 14 horas, para ajuste da taxa de lotação. Foram utilizados quatro animais-testes por unidade experimental, escolhidos aleatoriamente no rebanho disponível. Os animais tiveram livre acesso a sal comum e água em todos os piquetes e o controle sanitário foi realizado de acordo com o calendário da unidade.

A estimativa da taxa de acúmulo de forragem foi realizada a cada 28 dias pela metodologia do triplo emparelhamento (Moraes et al., 1990) utilizando-se cinco gaiolas de exclusão em cada unidade experimental. As amostras de dentro e fora da gaiola foram cortadas, rente ao solo, em um quadrado com $0,25 \mathrm{~m}^{2}$, e separadas em material morto e vivo e, depois, nos componentes gramíneas, leguminosas, ciperáceas e outras famílias. Após separação, as amostras foram colocadas em estufa de ar forçado, em temperatura média de $60^{\circ} \mathrm{C}$, até peso constante, e pesadas. O somatório dos componentes verdes (excetuando-se outras famílias) permitiu o cálculo da matéria seca da forragem verde (MSFV). Utilizando-se a diferença do peso verde seco entre as amostras de dentro e fora de gaiola, dividida pelo número de dias transcorridos, definiu-se a taxa de acúmulo de matéria seca da forragem verde.

A avaliação da massa de forragem também foi feita no intervalo de 28 dias, antecedendo as pesagens dos animais para ajuste das ofertas pretendidas. Para estimar a massa, utilizou-se a técnica da dupla amostragem (Haydock \& Shaw, 1975), com 80 estimativas visuais por unidade experimental em cada ocasião.

O valor da taxa de lotação em cada piquete foi calculado a partir dos dados de massa de matéria seca da forragem verde (MSFV), taxa de acúmulo de MSFV e oferta pretendida de MSFV. O valor de MSFV foi dividido por 28 (número de dias entre pesagens) e acrescido da taxa diária de acúmulo de MSFV estimada para o período. Desta forma, obteve-se a disponibilidade diária de MSFV, que foi 
multiplicada por 100 e dividida pelo valor de oferta pretendida para cada oferta de forragem e multiplicada pela área do piquete para obtenção da taxa de lotação necessária para manter a oferta desejada.

As avaliações de estrutura do pasto foram realizadas em quatro oportunidades, uma em cada estação do ano (verão: 6 a 9/2/2006; outono: 28/5 a 4/6/2006; inverno: 25 a 28/8/2006; primavera: 25 a 28/11/2006), considerando a cobertura do estrato superior (\%), a cobertura do estrato inferior (\%), a altura do estrato superior $(\mathrm{cm})$ e a altura do estrato inferior $(\mathrm{cm})$. De acordo com as características da vegetação local, definiu-se como estrato superior aquele formado por plantas de estrutura ereta, cespitosa e com altura mínima de $15 \mathrm{~cm}$; e como estrato inferior ao das demais plantas que não atendiam a este quesito.

As espécies e os grupos considerados foram aqueles com ocorrência relevante na área, determinada pelo levantamento florístico, pela escala de Braun-Blanquet (1964), modificada por Mueller-Dombois \& Ellenberg (1974), cujos resultados foram descritos por Castilhos et al. (2006). As principais espécies foram: caraguatá (Eryngium horridum (Spreng.) Less), carqueja (Baccharis trimera (Less) DC.), chirca (Eupatorium buniifolium Hook et Arn), macegaestaladeira (Saccharum trinii (Hack.) Renv.) e mio-mio (Baccharis coridifolia DC.); e os grupos: ciperáceas (Carex phalaroides Kunth, C. sororia Kunth, C. seticulmis Boeck., C. bonariensis Desf. ex Poir., Cyperus luzulae (L.) Rottb. ex Retz. e Eleocharis viridans Kük. ex Osten), gramíneas (Axonopus affinis Chase, Coelorachis selloana (Hack.) Henrard, Piptochaetium montevidense (Spreng.) Herter, Paspalum notatum Flüggé, Steinchisma hians (Elliott) Nash, $P$. dilatatum Poir e $P$. plicatulum Michx.), juncáceas (Juncus sp., Juncus microcephalus Kunth, J. dichotomus Elliott, J. tenuis Willd.) e leguminosas (Desmodium incanum DC., Medicago lupulina L.).

As características estruturais foram determinadas em 80 retângulos por unidade experimental $(1,0 \times 1,5 \mathrm{~m})$ distribuídos em quatro transectas para cada piquete. $\mathrm{O}$ tamanho dessas transectas variou conforme a área do piquete e o retângulo de amostragem foi disposto de forma eqüidistante e proporcional sobre cada transecta. Para estimar as porcentagens de cobertura de cada estrato, o retângulo foi dividido em 100 partes iguais, considerando o percentual de ocupação da projeção das plantas que formavam o estrato superior e, por diferença, a de estrato inferior.

Para as leituras de altura dos estratos superior e inferior, o retângulo amostral foi dividido em seis partes de $0,5 \times 0,5 \mathrm{~m}$ para a leitura de cada estrato, de forma propor- cional à porcentagem de cobertura dos estratos. A cada $15 \%$ de cobertura do estrato, era realizada uma leitura de altura nesse estrato, totalizando sempre seis leituras por retângulo. A leitura da altura foi realizada utilizando-se régua graduada (sward stick - Barthram, 1985). Com o toque da régua na primeira folha verde da planta, mediu-se a altura, determinou-se a espécie ou o grupo pertencente (dados não apresentados) e anotou-se a condição da planta (pastejada ou não pastejada).

As avaliações do comportamento ingestivo foram subseqüentes às avaliações de caracterização da estrutura do pasto. Os registros dos dados foram feitos em dois dias consecutivos de cada estação (verão: 10 e 11/2/2006; outono: 5 e 6/6/2006; inverno: 29 e 30/8/2006; primavera: 29 e 30/11/2006) e, para fins de análise, utilizou-se o valor médio dos dois dias. As avaliações foram feitas por observação visual, em intervalos regulares de 10 minutos, do nascente até o pôr-do-sol, utilizando-se o método proposto por Hughes \& Reid (1951).

Os observadores foram previamente treinados, alocados individualmente em cada unidade experimental, montados a cavalo e utilizando binóculos para facilitar a visualização dos animais. Os quatro animais-testes de cada unidade experimental foram numerados com tinta alumínio nas duas laterais da região toráxica para identificação.

As atividades de cada animal foram classificadas como: tempo de pastejo - atividade de procura, seleção e colheita de forragem na pastagem; tempo de ruminação - período em que o animal esteve mastigando o bolo alimentar retornado do rúmen; e tempo de outras atividades - período em que o animal esteve interagindo socialmente, em deslocamento, descansando, bebendo água ou no saleiro.

Uma vez que as observações visuais foram realizadas no período diurno, que varia entre estações do ano, para efeito de comparação de tratamentos, padronizaram-se os tempos de cada atividade como percentual do tempo total avaliado, de modo a permitir as avaliações nas estações do ano em mesma base comparativa. O tempo diário médio de avaliação foi de 856 minutos nos dias 10 e 11 de fevereiro (verão), 670 minutos nos dias 5 e 6 de junho (outono), 719 minutos nos dias 29 e 30 de agosto (inverno) e 890 minutos nos dias 29 e 30 de novembro de 2006 (primavera).

O número de refeições (Nref), a duração das refeições (Tref), o número de intervalos de refeições (Ninterv) e a duração do intervalo de refeições (Tinterv) foram obtidos pelo controle do tempo de pastejo (Penning \& Rutter, 2004). A refeição foi caracterizada como período mínimo de 20 minutos no qual o animal se encontra em processo de pastejo. Para caracterizar um intervalo de refeições, consi- 
derou-se uma pausa mínima, também de 20 minutos, no processo de pastejo.

Os dados foram submetidos à análise de variância e ao teste F a $10 \%$ de significância, utilizando-se o procedimento MIXED do pacote estatístico SAS (2001) com medidas repetidas no tempo (estações do ano). Quando detectadas diferenças, as médias foram comparadas pelo teste $\mathrm{t}$ de Student (PDIFF). Foram realizados testes de correlação e regressão polinomial e, sempre que a função-resposta foi significativa $(\mathrm{P}<0,10)$, optou-se por apresentar os resultados pela equação de regressão de maior coeficiente de determinação $\left(R^{2}\right)$.

\section{Resultados e Discussão}

Não houve interação ofertas de forragem $\times$ estação do ano $(\mathrm{P}>0,10)$ para a condição do pasto e a intensidade de pastejo (Tabela 1), avaliadas por meio da oferta real e da massa de forragem nos períodos imediatamente anteriores às avaliações do comportamento ingestivo.

As ofertas reais praticadas nos períodos indicam que as ofertas de forragem pretendidas foram efetivas em promover contrastes de níveis de alimentação, pois houve diferença significativa entre eles $(\mathrm{P}<0,10)$, com valores próximos aos pretendidos.

Os efeitos dos níveis de oferta sobre a massa de forragem seguiram tendências clássicas já demonstradas em trabalhos similares sobre pastagens naturais do Rio Grande do Sul (Maraschin, 2001; Nabinger, 2006). Os efeitos da estação do ano indicam que o verão e a primavera são as estações do ano que possibilitam maior massa de forragem, em decorrência do clima favorável predominante.
Neste trabalho, será discutida somente a participação do estrato superior na estrutura do pasto, pois é o inverso da participação do estrato inferior. Houve interação ofertas de forragem $\times$ estações do ano $(\mathrm{P}<0,10)$ para cobertura do estrato superior, contudo, apenas na primavera a cobertura do estrato superior variou conforme a oferta de forragem (Figura 1A).

A resposta observada na primavera está relacionada ao consumo crescente de espécies do estrato superior, sobretudo macega-estaladeira (dados não apresentados), o que determinou diminuição da oferta de forragem para abaixo de $13,7 \%$ (ponto de máxima). Este maior consumo determina diminuição na cobertura desta espécie, embora não necessariamente altere sua freqüência. Nesta estação, normalmente ocorrem as maiores taxas de acúmulo de forragem (Maraschin, 2001), o que, aliado à roçada feita no final de fevereiro, determinou rebrote vigoroso da macegaestaladeira na primavera seguinte, quando é bem consumida pelos animais se a oferta for média ou baixa. Este padrão de resposta confirma o descrito por Setelich (1994), que verificou que menores ofertas diminuem tanto a densidade como o diâmetro das touceiras de Andropogon lateralis Ness, espécie de estrutura similar à da macega-estaladeira. Portanto, é na primavera que se cria boa parte da dupla estrutura desses campos, estrato superior e inferior, quando ocorre aumento da cobertura do estrato e os ritmos de acúmulo de matéria seca são superiores aos ritmos de ingestão dos animais.

A ausência de variação na cobertura do estrato superior no verão em resposta à oferta pode estar relacionada à condição fenológica das plantas desse estrato passíveis de consumo (macega-estaladeira e caraguatá), as quais se encontravam em estádio reprodutivo, dificultando o

Tabela 1 - Oferta real e massa de forragem ao longo do ano em pastagem natural

\begin{tabular}{|c|c|c|c|c|c|}
\hline \multirow[t]{2}{*}{ Oferta diária pretendida ( $\mathrm{kg}$ de $\mathrm{MSFV} / 100 \mathrm{~kg}$ de $\mathrm{PV}$ ) } & \multicolumn{4}{|c|}{ Estação do ano } & \multirow[t]{2}{*}{ Média } \\
\hline & Verão & Outono & Inverno & Primavera & \\
\hline \multicolumn{6}{|l|}{ Oferta real diária ( $\mathrm{kg}$ de MSFV/100 kg de PV) } \\
\hline 4 & 4,3 & 3,7 & 8,0 & 4,5 & $5,1 \mathrm{~d}$ \\
\hline 8 & 7,6 & 6,0 & 9,0 & 10,5 & $8,3 c$ \\
\hline 12 & 13,1 & 12,5 & 9,2 & 16,8 & $12,9 b$ \\
\hline 16 & 18,4 & 17,0 & 15,4 & 19,9 & $17,6 \mathrm{a}$ \\
\hline Média & 10,8 & 9,8 & 10,4 & 12,9 & \\
\hline \multicolumn{6}{|l|}{ Massa de forragem (kg de MSFV/ha) } \\
\hline 4 & 444,5 & 264,5 & 413,1 & 580,7 & $425,7 \mathrm{c}$ \\
\hline 8 & 543,8 & 341,9 & 363,2 & 735,2 & $496,0 \mathrm{bc}$ \\
\hline 12 & 614,7 & 675,5 & 456,6 & 908,1 & $663,7 \mathrm{ab}$ \\
\hline 16 & 870,4 & 688,0 & 538,8 & 1084,5 & $795,4 \mathrm{a}$ \\
\hline Média & $618,3 \mathrm{ab}$ & $492,5 b$ & $442,9 b$ & $827,1 \mathrm{a}$ & \\
\hline
\end{tabular}

${ }^{1}$ Médias seguidas da mesma letra na linha ou coluna não diferem $(\mathrm{P}>0,10)$ significativamente entre si. 

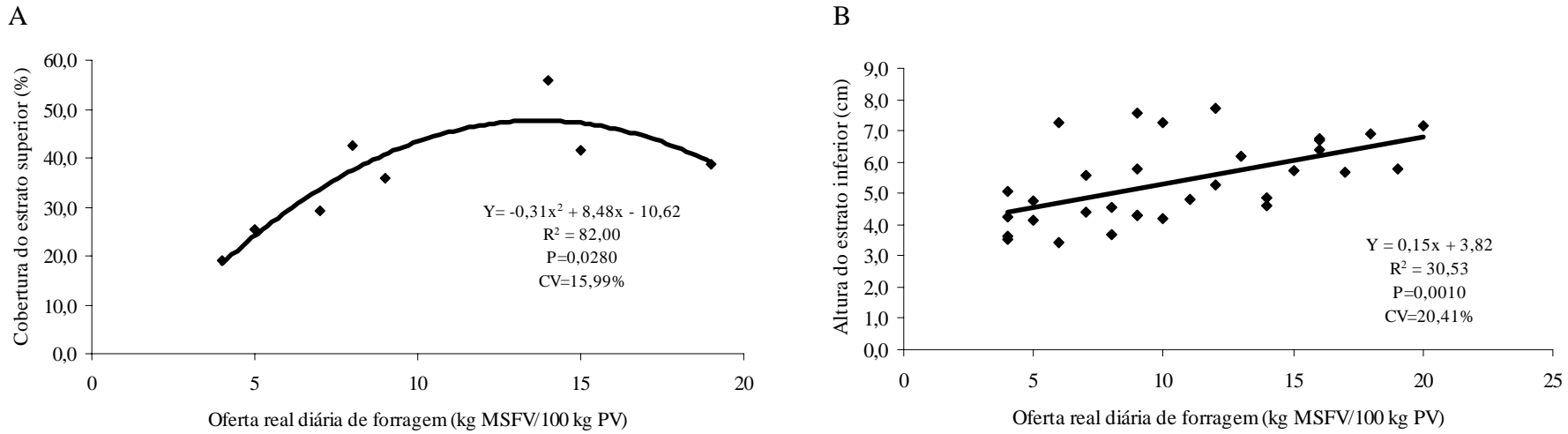

Figura 1 - Percentual de cobertura do estrato superior na primavera (A) e altura do estrato inferior na média das estações do ano (B) da pastagem natural em resposta a níveis de oferta real diária de forragem.

pastejo dos animais. No outono e inverno, a roçada determinou a alteração desta condição estrutural (eliminação de colmos floríferos) diminuindo, e de certa forma uniformizando, a freqüência de cobertura.

As alturas dos estratos superior e inferior foram afetadas $(\mathrm{P}<0,10)$ pelas estações do ano (Tabela 2), mas não responderam às ofertas de forragem avaliadas. No estrato superior, a roçada teve efeito claro na variação da altura, diminuindo-a significativamente $(\mathrm{P}<0,0001)$ nos períodos de outono e inverno em relação ao verão anterior e à primavera seguinte. No outono e inverno, as alturas de cada estrato são semelhantes e variam pouco, enquanto na primavera a altura do estrato superior praticamente é duplicada em relação à do inverno, atingindo valor semelhante ao da altura do verão anterior.

No estrato inferior, a maior altura é observada no verão $(\mathrm{P}=0,0052)$. No outono e inverno, diminui com a redução ou paralisação do crescimento da maioria das espécies que o compõem e com o pastejo preferencial dos animais neste estrato. A altura do estrato inferior tende a aumentar na primavera com o aumento das taxas de crescimento. Variações das alturas do estrato inferior nas estações do ano também foram observadas por Santos (2007) em pastagem natural da Depressão Central do Rio Grande do Sul, onde verificou valores de $7,0 \mathrm{~cm}$ no verão, $6,7 \mathrm{~cm}$ no outono, $5,5 \mathrm{~cm}$ no inverno e $7,0 \mathrm{~cm}$ na primavera. As alturas observadas neste estudo foram ligeiramente inferiores às obtidas por esse autor, entretanto, as tendências de aumento e diminuição da altura nas estações são idênticas.

Não houve interação oferta $\times$ estação do ano para altura dos estratos $(\mathrm{P}>0,10)$. As ofertas de forragem também não afetaram a altura do estrato superior $(\mathrm{P}>0,10)$, cuja média foi de $37,1 \mathrm{~cm}$, porém determinaram efeito linear e positivo (Figura 1B) sobre a altura do estrato inferior $(\mathrm{P}=0,0010)$.

A elevada dispersão de pontos observada no verão, possivelmente causada pela estiagem, foi a responsável pelo baixo coeficiente de determinação observado para o ajuste no estrato inferior. Quando se excluiu o verão dessa análise, observou-se melhor ajuste da equação ( $\left.\hat{Y}=0,16 x+3,17 ; R^{2}=62,30 ; P<0,001\right)$, com pouca mudança em seus coeficientes, o que indica a consistência do efeito da oferta sobre a altura.

Considerando que nessas pastagens há dupla estrutura de dossel, Soares et al. (2005) sugeriram relacionar a variável animais ao estrato efetivamente pastejado pelos animais, isto é, o estrato entre touceiras. Gonçalves et al. (2009), em pastagem natural da Depressão Central do Rio Grande do Sul, determinaram que a altura ideal para esse estrato é de $11,5 \mathrm{~cm}$ para que a taxa de ingestão de forragem pelas novilhas seja otimizada. Neste trabalho, apesar dos elevados níveis de oferta (até 19,9\%), não se atingiu a altura preconizada. O pequeno aumento da altura do estrato

Tabela 2 - Alturas dos estratos superior e inferior de pastagens naturais ao longo do ano

\begin{tabular}{|c|c|c|c|c|c|}
\hline \multirow[t]{2}{*}{ Estrato } & & \multicolumn{4}{|c|}{ Estação do ano } \\
\hline & & Verão2005/2006 & Outono 2006 & Inverno 2006 & Primavera 2006 \\
\hline & & \multicolumn{4}{|c|}{ Altura média $(\mathrm{cm})^{1}$} \\
\hline Superior & $\mathrm{P}<0,0001$ & $51,0 \mathrm{a}$ & $25,6 b$ & $27,8 b$ & $46,0 \mathrm{a}$ \\
\hline Inferior & $\mathrm{P}=0,0052$ & $6,7 \mathrm{a}$ & $5,2 \mathrm{~b}$ & $4,5 b$ & $5,2 \mathrm{~b}$ \\
\hline
\end{tabular}

${ }^{1}$ Médias seguidas da mesma letra na linha não diferem $(\mathrm{P}>0,10)$ significativamente entre si. 
inferior com a elevação da oferta de forragem pode ser atribuído ao concomitante aumento da cobertura do estrato superior, composto por espécies pouco consumidas e que passam a ocupar área crescente da pastagem (Setelich, 1994; Santos, 2007), determinando maior pressão de pastejo sobre o estrato inferior.

Tendo em vista que, sobretudo em pastagens heterogêneas, os efeitos das ofertas de forragem sobre o desempenho animal podem ser indiretos, via estrutura do pasto, buscou-se verificar quais componentes desta estrutura estariam relacionados ao comportamento dos animais em pastejo.

O tempo de pastejo e o tempo de ruminação foram afetados $(\mathrm{P}<0,10)$ pela estrutura, representada pelo percentual de cobertura do estrato superior, independentemente das estações do ano (Figura 2A).

O tempo de pastejo se correlacionou de forma linear e negativa $(\mathrm{r}=-0,65 ; \mathrm{P}<0,0001)$ com o percentual de cobertura do estrato superior. Esse resultado pode estar relacionado ao aumento da oferta de forragem, que determina aumento da altura do estrato inferior, variável negativamente relacionada ao tempo de pastejo (Pinto et al., 2007), ou ao aumento, sobretudo na primavera, do consumo de plantas do estrato superior, o que aumenta a forragem de oferta. Mesmo com maior oferta de forragem, aproximadamente $40 \%$ das plantas avaliadas no estrato superior apresentavam sinais de pastejo. No entanto, é difícil afirmar que sua participação na dieta alcance proporção capaz de alterar o comportamento ingestivo. Para essas inferências, seria necessário o registro do tempo de pastejo dedicado a cada um dos estratos, o que exigiria sua identificação, não somente de forma concomitante à observação dos animais, mas também de forma visual, com evidentes limitações metodológicas.
O tempo de ruminação se correlacionou positiva e significativamente $(\mathrm{r}=0,51 ; \mathrm{P}=0,0029)$ ao percentual de estrato superior existente (Figura 2A). Esse resultado está de acordo com a diminuição do tempo de pastejo, pois essas variáveis são negativamente correlacionadas (Allden \& Whittaker, 1970; Penning et al., 1991; Hodgson et al., 1997). Pinto et al. (2007) em pastagem natural. Barbosa et al. (2009) e Baggio et al. (2008), em pastagem cultivada de inverno, também demonstraram relação entre essas atividades: conforme aumenta a oferta de forragem (com as alturas), os animais reduzem o tempo de pastejo e aumentam o tempo de ruminação.

No entanto, é importante considerar que, tanto para o tempo de pastejo como para o tempo de ruminação, os coeficientes de determinação são relativamente baixos (respectivamente 42,3 e 25,9), ou seja, apesar das altas significâncias das relações (Figura 2A), menos da metade da variação do tempo de pastejo e menos de um quarto da variação no tempo de ruminação pode ser explicada somente pela cobertura do estrato superior. Isso indica que outros atributos da vegetação do estrato superior, como a distribuição, a heterogeneidade e o nível de agregação, além do tamanho de touceiras, devem estar envolvidos na resposta e precisam ser estudados neste tipo de ambiente.

Além disso, essas mesmas variáveis, quando relacionadas à altura do estrato inferior, mostraram respostas significativas $(\mathrm{P}<0,10)$ e com coeficientes de determinação mais elevados (Figura 2B). O aumento da altura desse estrato explicou $51 \%$ do tempo de pastejo e $67 \%$ do tempo de ruminação, portanto, essa variável determina boa parte do comportamento ingestivo e pode ser conseqüência direta do acréscimo da oferta de forragem (Figura 1B).

No período do verão, não houve efeito significativo $(\mathrm{P}>0,10)$ da altura do estrato inferior sobre os tempos
A

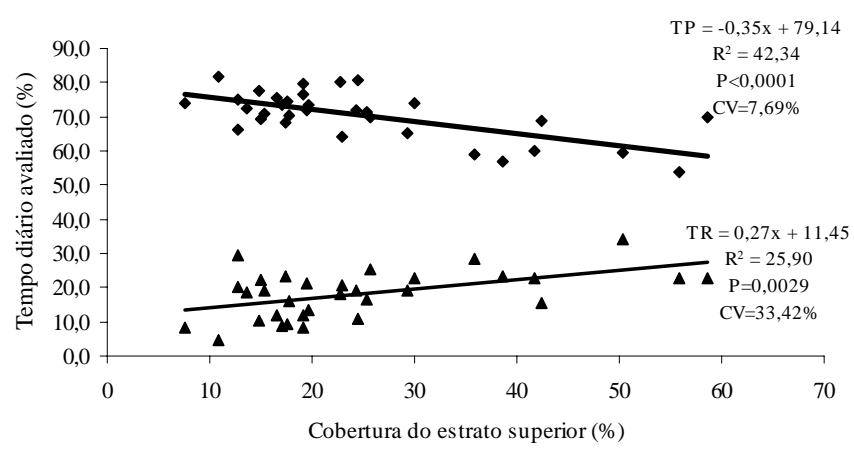

B

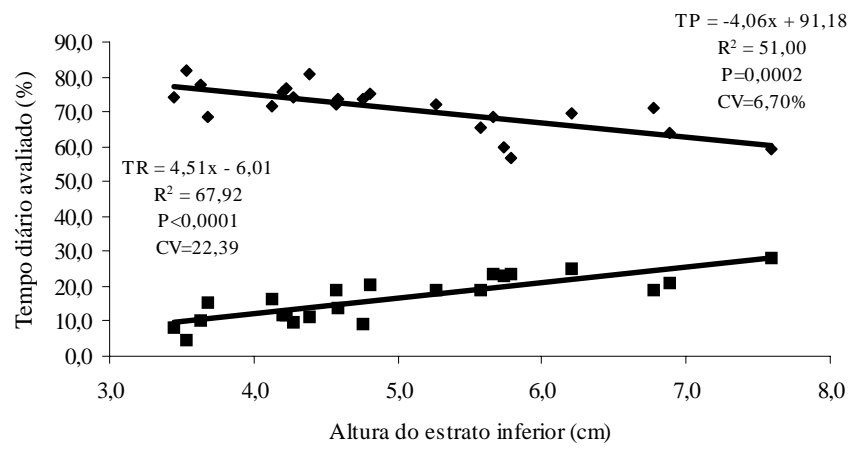

Figura 2 - Tempos diários de pastejo (TP) e ruminação (TR) de novilhos em pastagem nativa conforme o percentual de cobertura do estrato superior na média das estações do ano (A) e em relação à altura do estrato inferior no outono, inverno e primavera (B). Valores expressos em percentual do período diurno. 
diários de pastejo e ruminação, fato relacionado à estiagem observada no período, que, além de acarretar baixas alturas do estrato inferior, atuou como agente uniformizador das pastagens nas diversas ofertas de forragem. As médias dos tempos de pastejo e de ruminação nesta estação foram de $70,1+6,3 \%(600,0+54,0$ minutos $)$ e $23,4+5,9 \%(200,1+50,4$ minutos), respectivamente.

Considerando o tempo médio de avaliação (760 minutos para as estações de outono, inverno e primavera), pode-se estimar aumento de 34 minutos no tempo de ruminação em resposta a cada centímetro de aumento na altura do estrato inferior. Esse resultado confirma que o aumento do estrato inferior promove maiores massas de bocado.

Na média das estações (outono, inverno e primavera), verificou-se redução de 31 minutos no tempo de pastejo a cada centímetro de aumento na altura do estrato inferior. O tempo de pastejo apresentou taxa de decréscimo menor que a descrita em outros trabalhos, o que pode ser estar relacionado ao fato de que as alturas médias encontradas no estrato inferior foram menores que $8 \mathrm{~cm}$, bem aquém daquela de 11,5 cm preconizada por Gonçalves et al. (2009). Decréscimo no tempo de pastejo com o aumento da altura do estrato inferior em pastagens nativas da Depressão Central também foi relatado por Pinto et al. (2007) e ilustra a importância desse estrato na determinação do padrão de pastejo dos animais. Esses autores encontraram diminuição de aproximadamente 67 minutos no tempo de pastejo no verão para cada centímetro acrescido na altura do estrato inferior do pasto.

De acordo com Gordon (2000), em trabalho com vegetação nativa na Escócia, o padrão de pastejo está relacionado à dinâmica dos estratos inferior e superior, que dependem diretamente das intensidades de pastejo. Conforme descrito por Laca et al. (1992), o aumento do tempo de pastejo é uma estratégia dos animais para com-

A

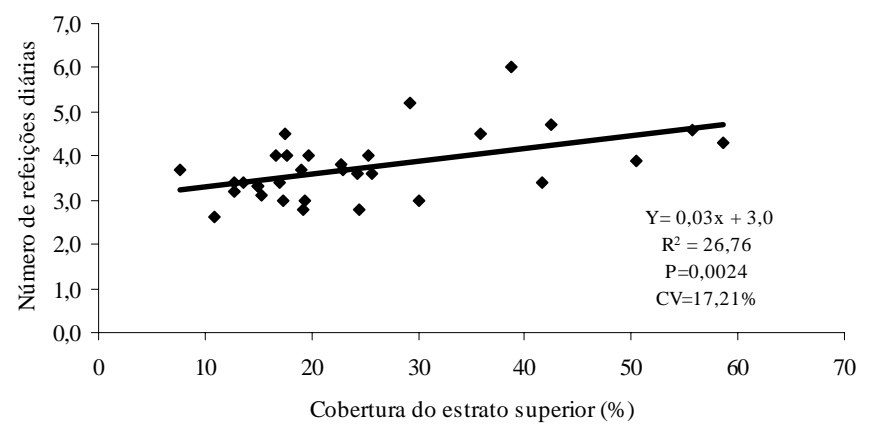

pensar a diminuição da massa do bocado em situações de baixa disponibilidade de forragem e para aumento do consumo de forragem.

A altura do estrato superior não apresentou correlação com nenhuma das variáveis relacionadas ao comportamento ingestivo $(\mathrm{P}>0,10)$.

O número de refeições não apresentou relação com a altura do estrato inferior em nenhuma das estações do ano, mas foi significativamente $(\mathrm{P}<0,10)$ afetado pelo percentual de cobertura do estrato superior (Figura 3A). Desse modo, o aumento do número de refeições fortaleceria a hipótese de que a maior oferta de forragem, responsável pelo aumento da altura do estrato inferior, juntamente com o aumento no percentual de estrato superior, propiciou ambiente alimentar mais adequado, conforme proposto por Carvalho \& Moraes (2005). Segundo esses autores, em situações adequadas de alimentação, os animais realizariam número maior de refeições, de menor duração, expressando ciclos mais rápidos de saciedade/fome (interrupção de pastejo/motivação ao pastejo).

O número de intervalos de refeições também se mostrou correlacionado positivamente com o percentual de estrato superior $(\mathrm{r}=0,47 ; \mathrm{P}=0,0068)$ e com a altura do estrato inferior no outono $\left(\hat{\mathrm{Y}}=0,26 \mathrm{X}+1,01 ; \mathrm{R}^{2}=55,97 ; \mathrm{P}=0,0328\right.$; $\mathrm{CV}=14,01 \%)$.

O aumento no número de intervalos de refeições ocorreu juntamente com o aumento do percentual de estrato superior, até que o máximo de $42,1 \%$ desse estrato foi atingido, quando o número de intervalos tendeu a se estabilizar ou decrescer (Figura 3B). Essa estabilização do número de intervalos em situações de elevado percentual de estrato superior é rara, pois o aumento linear do número de refeições é acompanhado de forma idêntica pelo número de intervalo de refeições, pois são variáveis recíprocas (Carvalho \& Moraes, 2005).

B

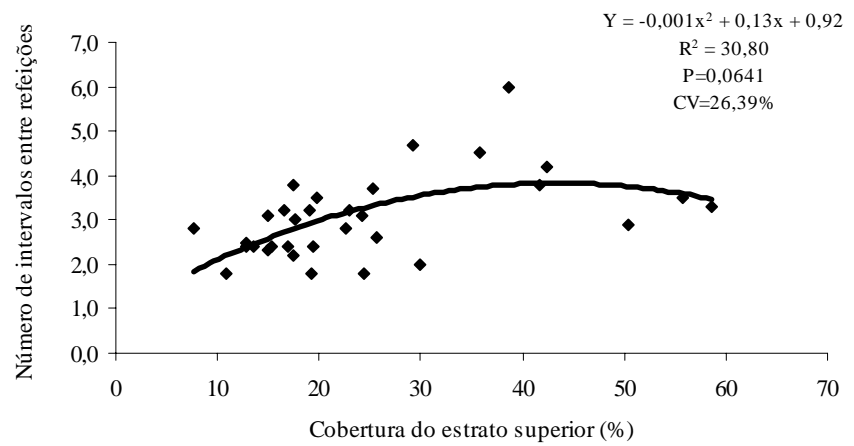

Figura 3 - Relação entre o percentual de estrato superior e o número de refeições (A) e entre o número de intervalos de refeições (B) de novilhos em pastagem nativa manejada com diferentes ofertas de forragem. 
As demais variáveis analisadas, referentes ao comportamento em pastejo, não apresentaram respostas conclusivas. Por exemplo, o intervalo de refeições, a duração das refeições e a duração dos intervalos (em minutos) foram influenciadas somente pela altura do estrato inferior e apenas no outono $(\mathrm{P}<0,10)$. Desta forma, nesta estação, a resposta do intervalo de refeições foi descrita como $\hat{\mathrm{Y}}=4,86 \mathrm{X}+47,03\left(\mathrm{R}^{2}=51,12\right.$; $\mathrm{P}=0,0385 ; \mathrm{CV}=9,46 \%)$; a duração das refeições como $\hat{\mathrm{Y}}=-13,57 \mathrm{X}+230,0\left(\mathrm{R}^{2}=50,69 ; \mathrm{P}=0,0476 ; \mathrm{CV}=12,04\right) ; \mathrm{eo}$ número de intervalos como $\hat{\mathrm{Y}}=0,26 \mathrm{X}+1,01\left(\mathrm{R}^{2}=55,97\right.$; $\mathrm{P}=0,0328 ; \mathrm{CV}=14,01 \%)$. Também houve efeito significativo $(\mathrm{P}<0,10)$ da altura do estrato inferior sobre a duração dos intervalos de refeições no inverno ( $\hat{\mathrm{Y}}=18,84 \mathrm{X}-25,92$; $\mathrm{R}^{2}=69,94 ; \mathrm{P}=0,0097 ; \mathrm{CV}=14,26 \%$ ).

É provável que a falta de resposta destas variáveis à altura do estrato inferior, tanto no verão como no inverno e na primavera, deva-se ao consumo variável de alguma espécie do estrato superior (possivelmente a macegaestaladeira), o que poderia estar afetando de forma nãosistemática, por exemplo, o tempo de manipulação do bocado e, conseqüentemente, a duração e o intervalo de refeições. A taxa de bocados, o tempo de manipulação e a participação dos estratos na dieta poderiam ser variáveis explicativas destas respostas, mas não foram avaliadas neste trabalho.

As respostas significativas $(\mathrm{P}<0,10)$ observadas no outono podem ser atribuídas, inicialmente, à maior participação do estrato inferior na dieta, uma vez que o estrato superior havia sido roçado. Apesar da rebrota e do consumo da macega-estaladeira, a uniformidade desta rebrota e o tamanho menor das folhas produzidas após a roçada podem ter determinado consumo mais sistemático e regular (independentemente de seu percentual de cobertura), determinando o efeito significativo da altura do estrato inferior. Carvalho \& Moraes (2005) caracterizaram o maior número de refeições e a menor duração da refeição em pastagens de maior altura, ou de maior massa. A tendência dos tempos de refeição e intervalos de refeições no outono com o aumento da altura do estrato inferior também estão de acordo com as ponderações desses autores, pois a relação inversa entre as variáveis é um comportamento esperado com o aumento das alturas do estrato.

\section{Conclusões}

O nível de oferta de forragem aplicada em pastagem natural afeta a estrutura do pasto, pois promove alterações na proporção de área ocupada pelo estrato superior e pelo aumento da altura do estrato inferior. $\mathrm{O}$ aumento da oferta de forragem e da altura do estrato inferior determina resposta linear decrescente do tempo de pastejo, caracterizando também ambiente alimentar com maior número e menor tempo de duração das refeições.

\section{Agradecimentos}

À zootecnista Carolina Bremm, pelo valioso auxílio estatístico e pela amizade, aos funcionários da Unidade Fepagro Campanha e ao Sr. Floriano Tomé, pela cooperação e ajuda constantes, aos bolsistas da Embrapa Pecuária Sul e a todos que se propuseram a participar das avaliações.

\section{Literatura Citada}

ALLDEN, W.G.; WHITTAKER, McD. The determinants of herbage intake by grazing sheep: the interrelationship of factors influencing herbage intake and availability. Australian Journal of Agricultural Research, v.21, p.755-766, 1970.

BAGGiO, C.; CARVALHO, P.C.F.; SILVA, J.L.S. et al. Padrões de uso do tempo por novilhos em pastagem consorciada de azevém anual (Lolium multiflorum Lam.) e aveia preta (Avena strigosa Schreb). Revista Brasileira de Zootecnia, v.37, p.1912-1918, 2008.

BARBOSA, C.M.P.; CARVAlHO, P.C.F.; CAUDURO, G.F. et al. Componentes do pastejo de cordeiros em azevém (Lolium multiflorum L.) sob diferentes intensidades e métodos. Archivos de Zootecnia, 2009 (no prelo).

BARTHRAM, G.T. Experimental techniques: the HFRO sward stick. Aberdeen: Hill Farming Research Organization, 1985. p.29-30. (Bienal Report).

CARVALHO, P.C.F.; SANTOS, D.T.; NEVES, F.P. Oferta de forragem como condicionadora da estrutura do pasto e do desempenho animal. In: SIMPÓSIO DE FORRAGEIRAS E PROdUÇÃo Animal, 2., 2007, Porto Alegre. Anais... Porto Alegre: Universidade Federal do Rio Grande do Sul, 2007. p.83-121.

CARVAlHO, P.C.F.; MORAES, A. Comportamento ingestivo de ruminantes: bases para o manejo sustentável do pasto. In: MANEJO SUSTENTÁVEL EM PASTAGEM, 2005, Maringá. Palestras... Maringá, 2005. p.1-20.

CARVAlHO, P.C.F.; RIBEIRO FILHO, M.N.; POLI, C.H.E.C. et al. Importância da estrutura da pastagem na ingestão e seleção de dietas pelo animal em pastejo. In: REUNIÃO ANUAL DA SOCIEDADE BRASILEIRA DE ZOOTECNIA, 38., 2001, Piracicaba. Anais... Piracicaba: Sociedade Brasileira de Zootecnia, 2001. p.853-871.

CARVALHO, P.C.F.; PRACHE, S.; DAMASCENO, J.C. O processo de pastejo: desafios da procura e apreensão da forragem pelo herbívoro. In: REUNIÃO ANUAL DA SOCIEDADE BRASILEIRA DE ZootecniA, 36., 1999, Porto Alegre. Anais... Porto Alegre: Sociedade Brasileira de Zootecnia, 1999. p.253-268.

CASTILHOS, Z.M.; BOLDRINI, I.I; PINTO, M.F. et al. Composição florística de campo nativo sob diferentes ofertas de forragem. In: CONGRESSO NACIONAL DE BOTÂNICA CONE SUL, 57., 2006, Gramado. Anais... Gramado: Sociedade Brasileira de Botânica [2006]. (CD- ROM).

GALLI, J.R.; CANGIANO, C.A.; FERNÁNDEZ, H.H. Comportamiento ingestivo y consumo de bovinos en pastoreo. Revista Argentina de Producción Animal, v.16, n.2, p.119142, 1996.

GONÇALVES, E.N.; CARVALHO, P.C.F.; KUNRATH, T.R. et al. Relações planta-animal em ambiente pastoril heterogêneo: processo de ingestão de forragem. Revista Brasileira de Zootecnia, 2009 (no prelo). 
GORDON, I.J. Plant-animal interactions in complex communities: from mechanism to modelling. In: HODGSON, J.; LEMAIRE G.; MORAES, A. et al. (Eds.). Grassland ecophysiology and grazing ecology. Wallingford: CAB International, 2000. p.191-207.

HAYDOCK, K.P.; SHAW, N.H. The comparative yield method for estimating dry matter yield of pasture. Australian Journal Agricultural and Animal Husbandry, v.15, n.76, p.66-70, 1975.

HODGSON, J.; COSGROVE, G.P.; WOODWARD, S.J.R. Research on foraging behavior: progress and priorities. In: INTERNATIONAL GRASSLAND CONGRESS, 18., 1997, Winnipeg. Proceedings... [S.1. : s.n.], 1997. (CD-ROM).

HODGSON, J. Ingestive behavior. In: LEAVER, J.D. (Ed.) Herbage intake handbook. Hurley: The Britsh Grassland Society, 1982. p.113-140.

HUGHES, G.P.; REID, D. Studies on the behavior of cattle and sheep in relation to utilization of grass. Journal of Agricultural Science, v.41, p.350-355, 1951.

LACA, E.A.; UNGAR, E.D.; SELIGMAN, N. Effects of sward height and bulk density on bite dimensions of cattle grazing homogeneous sward. Grass and Forage Science, v.47, p.91-102, 1992.

MARASCHIN, G.E. Production potential of South America grasslands. In: INTERNATIONAL GRASSLAND CONGRESS, 19., 2001, São Pedro. Proceedings... São Pedro: Fundação de Estudos Agrários Luiz de Queiroz, 2001. p.5-15.

MORAES, A.; MOOJEN, E.L.; MARASCHIN, G.E. Comparação de métodos de taxas de crescimento em uma pastagem submetida a diferentes pressões de pastejo. In: REUNIÃO ANUAL DA SOCIEDADE BRASILEIRA DE ZOOTECNIA, 27., 1990, Campinas. Anais... Campinas: Sociedade Brasileira de Zootecnia, 1990. p.332.

MOTT, G.O.; LUCAS, H.L. The design, conduct and interpretation of grazing trials on cultivated and improved pastures. In: INTERNATIONAL GRASSLAND CONGRESS, 6., 1952, Pasadena. Proceedings... Pasadena, 1952. p.1380-1385.

MUEller-Dombois, D.; EllenBerG, H. Aims and methods of vegetation ecology. New York: John Wiley, 1974. $547 \mathrm{p}$.

NABINGER, C. Manejo e produtividade das pastagens nativas do subtrópico brasileiro. In: SIMPÓSIO DE FORRAGEIRAS E
PROdUÇÃo Animal, 1., 2006, Porto Alegre. Anais... Porto Alegre: Universidade Federal do Rio Grande do Sul, 2006. p.25-76.

NABINGER, C. Princípios de exploração intensiva de pastagens. In: PEIXOTO, A.M.; MOURA, J.C.; FARIA, V.P. (Eds). Produção de bovinos a pasto. Piracicaba: Fundação de Estudos Agrários Luiz de Queiroz, 1997. p.15-95.

PALHANO, A.L.; CARVALHO, P.C.F.; DITTRICH, J.R. et al. Padrões de deslocamento e procura por forragem de novilhas leiteiras em pastagem de capim mombaça. Revista Brasileira de Zootecnia, v.35, p.2253-2259, 2006.

PALHANO, A.L.; CARVALHO, P.C.F.; BARRETO, M.Z. Influência da estrutura da pastagem na geometria do bocado e nos processos de procura e manipulação da forragem. Ciência e Cultura, v.31, p.33-52, 2002.

PENNING, P.D.; RUTTER, S.M. Ingestive behavior. In: BRITISH GRASSLAND SOCIETY (Ed.). Herbage intake handbook. 2.ed. Cirencester, 2004. p.151-175.

PENNING, P.D.; PARSONS, A.J.; ORR, R.J. et al. Intake and behaviour responses by sheep to changes in sward characteristics under continuous stoking. Grass and Forage Science, v.46, p.15-28, 1991 .

PINTO, C.E.; CARVAlHO, P.C.F.; FRIZZO, A. et al. Comportamento ingestivo de novilhos em pastagem nativa no Rio Grande do Sul. Revista Brasileira de Zootecnia, v.36, n.2, p.319-327, 2007

STATISTICAL ANALYSIS SYSTEM - SAS. System for Information: versão 8.02. Cary, 2001. (CD-ROM).

SANTOS, D.T. Manipulação da oferta de forragem em pastagem natural: efeitos sobre o ambiente de pastejo e o desenvolvimento de novilhas de corte. 2007. 260f. Tese (Doutorado em Zootecnia) - Universidade Federal do Rio Grande do Sul, Porto Alegre, 2007.

SETELICH, E.A. Potencial produtivo de uma pastagem natural do Rio Grande do Sul, submetida a distintas ofertas de forragem. 1994. 169f. Dissertação (Mestrado em Zootecnia) - Universidade Federal do Rio Grande do Sul, Porto Alegre, 1994.

SOARES, A.B.; CARVALHO, P.C.F.; NABINGER, C. et al. Produção animal e de forragem em pastagem nativa submetida a distintas ofertas de forragem. Ciência Rural, v.35, n.5, p.1148-1153, 2005 